\title{
Evaluation of Intermediate Annealing on Nb-Stabilized Ferritic Stainless Steel
}

\author{
Daniella Gomes Rodrigues ${ }^{a *}$, Cláudio Moreira Alcântara ${ }^{b}$, Tarcísio Reis de Oliveira ${ }^{b}$,
}

\author{
Berenice Mendonça Gonzalez ${ }^{a}$
}

\author{
${ }^{a}$ Departamento de Engenharia Metalúrgica e de Materiais, Universidade Federal de Minas Gerais, Av. \\ Antônio Carlos, 6627, Pampulha, Belo Horizonte, MG, Brazil \\ ${ }^{b}$ Aperam South America Research Center, Praça $1^{\circ}$ de Maio, 09, Centro, Timóteo, MG, Brazil
}

Received: December 11, 2016; Revised: May 24, 2017; Accepted: July 05, 2017

This study seeks to evaluate the effect of intermediate annealing on the microstructure, texture, and formability of $\mathrm{Nb}$-stabilized ferritic stainless steel. Two routes - direct cold rolling and cold rolling with an intermediate annealing were performed. The total reduction was $80 \%, 3-0.6 \mathrm{~mm}$ and 3-1.2-0.6 $\mathrm{mm}$. The characterization of the samples was conducted using X-ray diffraction, electron backscatter diffraction, and tensile tests to evaluate the formability by the average normal anisotropy coefficient, $\bar{r}$ value. The results showed that intermediate annealing promoted the strongest $\gamma$-fiber with peak at $\{111\}\langle 112\rangle$ and weak $\alpha$-fiber after cold rolling. After the final annealing, it was observed that intermediate annealing reduces the banded microstructure and $\theta$-fiber, and improves the $\gamma$-fiber uniformity and the $\bar{r}$ value. It is worth noting that the $\gamma$-fiber fraction was the same for direct reduction. The increase in $\bar{r}$ value was related to the reduction in $\theta$-fiber and the uniformity of texture recrystallization.

Keywords: ferritic stainless steels, intermediate annealing, cold rolling, texture

\section{Introduction}

The combination of corrosion resistance and mechanical proprieties allows for diverse applications of ferritic stainless steels (FSS). Other features displayed by FSS are high thermal conductivity, superficial quality, and low cost due to the absence of nickel ${ }^{1,2}$. These alloys are used in automotive exhaust systems, sinks, home appliances, elevator panels, and heaters ${ }^{3-5}$.

The thermomechanical processes affect the formation of the microstructure, crystallographic texture, and proprieties of steels. The FSS are produced by continuous casting, hot rolling, annealing of hot rolling coils, cold rolling, and recrystallization annealing ${ }^{6}$. An intermediate annealing in cold rolling was used to improve the recrystallization texture, increase the $\{111\}$ plans parallel to the sheet plane $(\gamma$-fiber), and reduced the roping defects ${ }^{7-9}$.

For some applications, it is desirable that FSS show a high average normal anisotropy coefficient ( $\bar{r}$ value), which is related to the $\gamma$-fiber recrystallization texture. Huh and Engler ${ }^{7}$ cited that an improvement in formability can be obtained by controlling the crystallographic texture. Control methods for the improvement of the $\gamma$-fiber recrystallization texture have been attempted by some approaches, such as refinement of the hot rolled microstructure, annealing of the hot rolled bands, optimization of cold rolling, intermediate annealing in cold rolling, and reduction of carbon in a solid solution $^{10-12}$.
The present work aimed to investigate the effect of intermediate annealing on the microstructure, texture, and formability of a niobium stabilized ferritic stainless steel.

\section{Materials and Methods}

The steel studied in the present work was an Nb-stabilized ferritic stainless steel. The chemical composition under investigation was $0.021 \% \mathrm{C}, 0.024 \% \mathrm{~N}, 16.0 \% \mathrm{Cr}, 0.35$ $\% \mathrm{Nb}, 0.30 \% \mathrm{Si}, 0.22 \% \mathrm{Ni}$, and $0.20 \% \mathrm{Mn}$. The chemical composition was provided by the Aperam South America. The samples were cut off after hot rolling and annealing in an industrial plant.

Cold rolling was performed by two routes: (i) direct reduction and (ii) reduction with intermediate annealing. In the first route, the samples were cold rolled from 3 to 0.6 $\mathrm{mm}$, producing an $80 \%$ reduction. In the second route, the samples were cold rolled from 3 to $1.2 \mathrm{~mm}$, annealed at $880^{\circ} \mathrm{C}$ for $24 \mathrm{~s}$, cold rolled from $1.2 \mathrm{~mm}$ to $0.6 \mathrm{~mm}$, producing a $50 \%$ final reduction. The final annealing was performed at $880^{\circ} \mathrm{C}$, with $24 \mathrm{~s}$ of soaking time for both routes.

The samples were characterized by X-ray diffraction (XRD) and electron backscatter diffraction (EBSD). The deformation textures were evaluated by XRD near the surface and in the central region. These were determined from the incomplete pole figures of (110), (200), and (211), using a Philips X'Pert PRO MPD texture diffractometer. The 
orientation distribution functions (ODF) were calculated by the series expansion method, according to Bunge $\left(l_{\max }=22\right)^{13}$. The recrystallization texture was determined by the EBSD in the longitudinal section thought thickness. The EBSD scans were performed in Philips XL-30 (LaB6 filament), equipped with a TSL EBSD system, with a step size ranging from 4 to $10 \mu \mathrm{m}$. The data obtained from EBSD were processed using the TSL-EDAX analysis software.

Tensile tests were performed to determine the average normal anisotropy coefficient ( $\overline{\mathrm{r}}$ value) and the planar coefficient of anisotropy $(\Delta r)$ in samples after the final annealing. The samples with a gauge length of $50 \mathrm{~mm}$ and width of $20 \mathrm{~mm}$ were cut-off at angles of $0^{\circ}, 45^{\circ}$, and $90^{\circ}$ to the rolling direction $(\mathrm{RD})$.

\section{Results}

\subsection{Starting material - hot rolled sample}

Figure 1 displays the microstructure and micro-texture through-thickness of the annealed hot rolled sample, where $\mathrm{ND}$ is the normal direction and $\mathrm{RD}$ is the rolling direction. From Figure 1a, it can be noted that the grain size distribution was heterogeneous along the thickness, with fine grains found near the surface and coarse grains found in the central region. The average grain size near the surface and in the central region was $22.20 \pm 1.38$ and $48.99 \pm 3.15 \mu \mathrm{m}$, respectively. The micro-texture also showed notable differences. The global texture showed in Fig. $1 \mathrm{~b}$ displays the $\alpha$-fiber $(\langle 110\rangle / / \mathrm{RD})$ that is more intense than the $\gamma$-fiber $(\{111\} / / N D)$. The peak occurred at $\{225\}\langle 110\rangle, f(g)=2.4$. Among the shear components, the $\{110\}\langle 001\rangle$ Goss component showed $f(g)$ $=1.6$. Near the surface, indicated by the black rectangle, the predominant texture was $\{011\} / / \mathrm{ND}$, comprising the shear texture (Fig. 1c). In the central region, the $\{112\} / / N D$ grains were more developed, while the $\{111\} / / \mathrm{ND}$ showed weak intensity (Fig. 1d).

\subsection{Evolution of the texture and microstructure for direct rolling}

Figure 2 shows the macro-texture obtained from XRD after an $80 \%$ reduction, first route. The analyses were performed close to the surface and in the center of the thickness. From Fig. $2 a$ and $2 b$, it was observed that the $\gamma$ and $\alpha$-fibers were developed in both regions. In the central region, the $\alpha$-fiber was strongest when reaching a peak of $\{001\}\langle 110\rangle, f(g)=13.8$. Close to the surface, the $\gamma$-fiber was more homogenous than in the central region, the maximum occurred at $\{111\}\langle 110\rangle$ in both regions. Furthermore, the shear components were not observed in the two regions.

Figure 3 displays the microstructure and texture after the final annealing. It can be noted from Fig. 3a that the microstructure and texture were heterogeneous along the thickness. The microstructure is formed by a cluster of
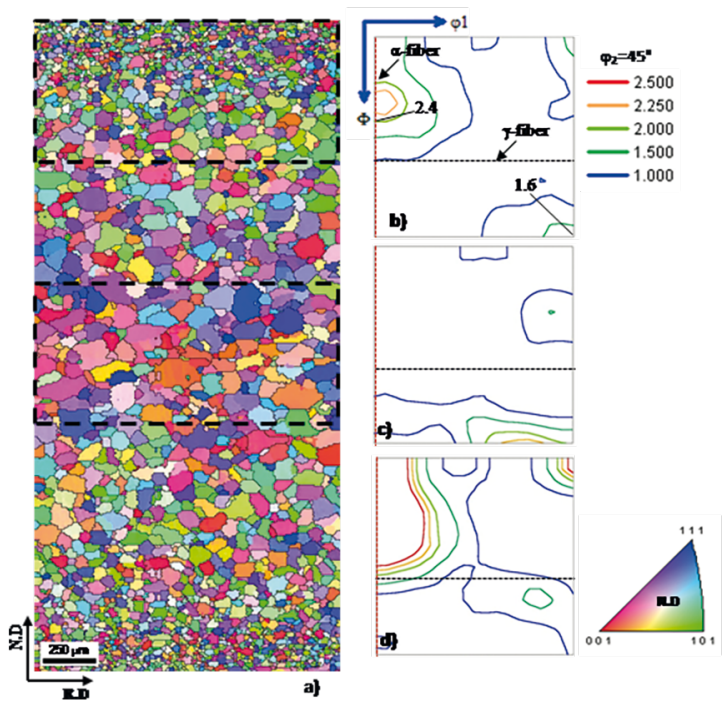

Figure 1. Microstructure and texture of annealed hot-rolled sample-a) orientation map. b) Global texture, $\phi_{2}=45^{\circ}$ ODF sections. c) Texture of the region near the surface. d) Texture of the central region.

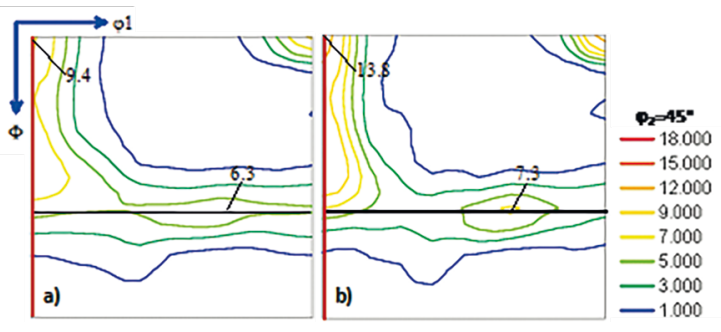

Figure 2. Macro-texture after $80 \%$ cold rolling: a) near the surface; b) center.

fine grains adjacent to the coarse grains, forming a duplex microstructure. The average grain size was $13.34 \pm 0.6 \mu \mathrm{m}$. It was observed that the $\{111\} / \mathrm{ND}$ grains were predominant, and some regions show various grains with the random orientations, as indicated by the yellow arrows. From Fig. $3 \mathrm{~b}$, it was observed that the $\gamma$-fiber was heterogeneous when reaching a peak at the $\{111\}\langle 121\rangle$ components, $f(g)=6.1$. Moreover, the $\{554\}\langle 225\rangle$ components were also developed.

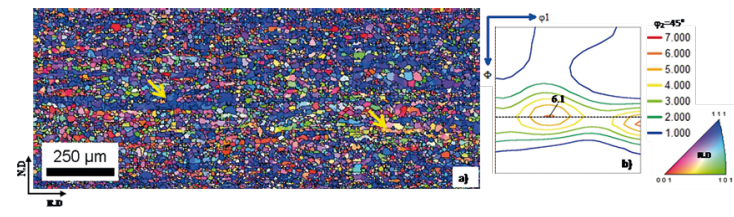

Figure 3. Microstructure and texture after annealing: a) orientation map; b) $\phi_{2}=45^{\circ} \mathrm{ODF}$ section.

\subsection{Evolution of the texture and microstructure for cold rolling with intermediate annealing}

Figure 4 shows the macro-texture obtained from XRD for the route with intermediate annealing. The macro-texture 
developed after a $60 \%$ reduction $(3-1.2 \mathrm{~mm})$ is shown in Fig. $4 \mathrm{a}$ (surface) and $4 \mathrm{~b}$ (center). It can be observed that the $\alpha$-fiber was strongest in the center region, reaching a maximum $f(g)=9.13$ at $\{335\}\langle 110\rangle$. The peak in the $\gamma$-fiber occurred at $\{111\}\langle 110\rangle, f(g)=5.8$. The notable difference between the surface and the center occurred in the intensity of the $\alpha$-fiber. The cold rolling texture after a $60 \%$ reduction developed a less pronounced texture than did that obtained in the direct reduction ( $80 \%$ reduction) (Fig. 2). In addition, the increase of deformation intensified the $\{111\}\langle 110\rangle$ component.

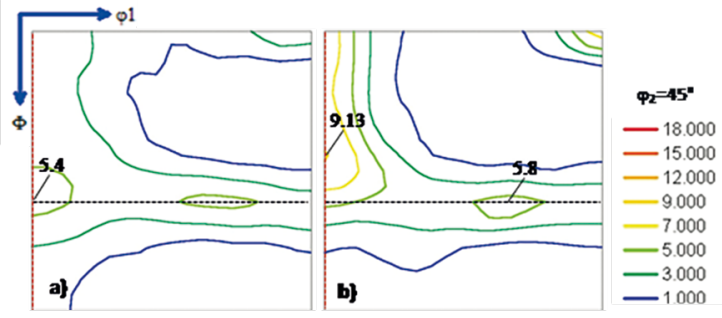

Figure 4. Macro-texture after $60 \%$ cold rolling: a) near the surface after the first reduction; b) center after the first reduction; $\phi_{2}=45^{\circ}$ ODF section.

The microstructure and texture development after the first annealing are shown in Figure 5. It can be noted that the microstructure is fully recrystallized, and the average grain size was $18.68 \pm 1.1 \mu \mathrm{m}$ (Fig. 5a). The area near the surface presented fine grains, while in the center region, the grains were slightly coarse. The resulting recrystallization texture is shown in Fig. 5b. It can be noticed that the $\gamma$-fiber was non-uniform when reaching a maximum at $\{111\}\langle 112\rangle$, $f(g)=2.9$. However, the $\{554\}\langle 225\rangle$ and $\{110\}\langle 001\rangle$ Goss components were also developed.

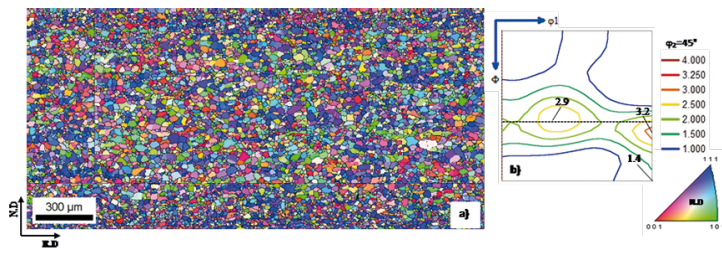

Figure 5. Micro-texture after $60 \%$ cold rolling and annealing: a) orientation map; b) $\phi_{2}=45^{\circ} \mathrm{ODF}$ section.

Figure 6 shows the macro-texture from XRD after the second cold rolling, from 1.2 to $0.6 \mathrm{~mm}$, from near the surface and in the center regions. The development of strong $\gamma$-fiber in these regions is presented in Fig. 6a and 6b. The main component developed was $\{111\}\langle 112\rangle$, with a peak near the surface, $f(g)=9.45$. In addition, the shifted components showed high intensity, as can be seen at $\{334\}\langle 483\rangle$. The $\alpha$-fiber proved to be weak, with a maximum occurring at $\{334\}\langle 110\rangle, f(g)=5$.6. Furthermore, some $\theta$-fiber components developed in both regions.

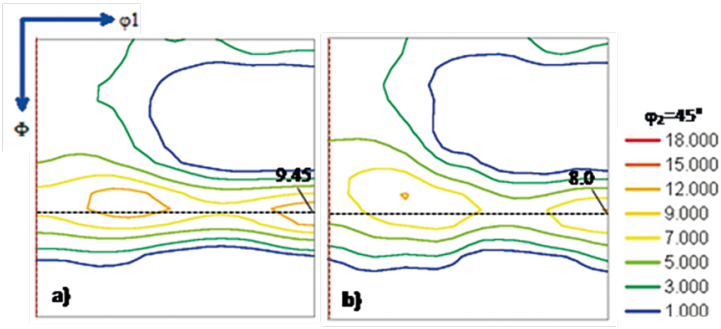

Figure 6. Macro-texture after 50\% cold rolling: a) near the surface after the second reduction; b) center after the second reduction; $\phi_{2}=45^{\circ}$ ODF section.

Figure 7 displays the microstructure and texture after the second annealing. It was noted that the microstructure was formed by recrystallized grains with an average grain size of $15.66 \pm 1.25 \mu \mathrm{m}$. The grain size distribution presented a highly homogenous through-thickness (Fig. 7a); differently from the result obtained to reduction direct (Fig.3). The predominant texture was the $\gamma$-fiber, reaching a peak at $\{111\}\langle 121\rangle, f(g)=4.4$ (Fig. $7 b$ ). It was observed that the developed $\gamma$-fiber was more uniform than in direct reduction route after annealing (Fig.3b).

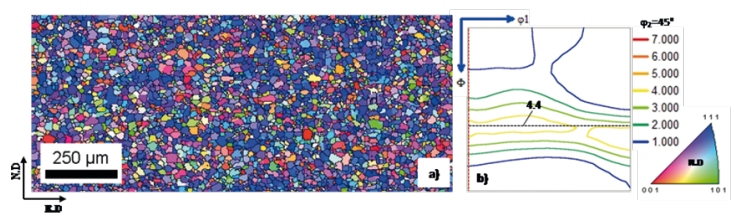

Figure 7. Micro-texture after 50\% cold rolling and annealing: a) orientation map; b) $\phi_{2}=45^{\circ} \mathrm{ODF}$ section.

\subsection{Formability, texture, gradient texture and banding factor}

The $\gamma$ and $\theta$-fiber fraction, uniformity and banding factor, normal anisotropy ( $\bar{r}$ value) and planar anisotropy coefficient $(\Delta \mathrm{r})$ are presented in Table 1 . The texture gradient can be expressed by the uniformity factor (UF) obtained from EBSD data. The value of $U F=0$ describes a perfectly homogeneous distribution, while a $U F=1$ describes a heterogeneous distribution. Similarly, the banding factor $(\mathrm{BF})$ describes the banding, where $B F=0$ denotes no banding and $B F=0.5$ describes a strong banded microstructure. It was observed that intermediate annealing improves the $\bar{r}$ value, but does not enhance the $\gamma$-fiber fraction. This route was favorable to reduce the $\theta$-fiber fraction from 0.11 to 0.08 and the banding factor, as well as to obtain a more homogenous distribution along the texture's thickness.

\section{Discussion}

The annealed hot-rolled sample showed the typical microstructure and texture of ferritic stainless steel (Fig.1). The microstructure and texture of the annealed hot-rolled 
Table 1. Coefficient of anisotropy and texture after the final annealing

\begin{tabular}{lccccccc}
\hline & $\bar{r}$ & $\Delta \mathrm{r}$ & $\gamma$ & $\theta$ & $\gamma / \theta$ & $\mathrm{UF}$ & $\mathrm{BF}$ \\
\hline Direct reduction & 1.35 & 0.52 & 0.43 & 0.11 & 3.91 & 0.070 & 0.020 \\
Reduction with intermediate annealing & 1.51 & 0.84 & 0.42 & 0.08 & 5.25 & 0.030 & 0.009 \\
\hline
\end{tabular}

sample presented remarkably different through-thickness. Close to the surface, the fine grains and shear texture, mainly the $\{110\}\langle 001\rangle$ Goss, were observed in Fig. 1. The development of the $\{110\}\langle 001\rangle$ Goss is attributed to the shear deformation on the surface ${ }^{14}$. However, the center region was formed by coarse grains and $\alpha$-fiber, reaching a peak at $\{225\}\langle 110\rangle$. According to Raabe and Lücke ${ }^{15}$, the thermal and stress profile during hot rolling produced differences between the surface and the center. Near the surface, the temperature was reduced due to the water sprayed during hot rolling, and shear deformation is predominant. On the other hand, in the center region, the temperature remains high and the deformation occurs by plain strain. Thus, the microstructure and texture heterogeneity occurred due to the steel production's thermomechanical process.

It was observed that the deformation texture after $80 \%$ cold rolling presented differences for both routes. The texture developed during cold rolling is directly related to the texture presented in the steel before deformation. In direct reduction, the prior material was the annealed hot-rolled sample (Fig.1). After cold rolling, it was noted that the $\alpha$-fiber was very intense, reaching a peak at $\{001\}\langle 011\rangle$, while the $\gamma$-fiber was weak, reaching a maximum at $\{111\}\langle 110\rangle$ (Fig 2). In addition, it was observed that the center region showed a more intense texture than did the region near the surface. The weak intensity close to the surface occurred due to the initial shear texture (Fig.1). However, the strongest $\alpha$-fiber in the center region was developed from the deformation and its already identified presence in the annealed hot-rolled sample. Similar results were reported in the literature for ferritic stainless steel ${ }^{7,14,15}$. For the intermediate annealing route, the previous material was the intermediate sample (Fig. 5). After cold rolling, the $\gamma$-fiber was more developed than the $\alpha$-fiber (Fig. 6), reaching a peak at $\{111\}\langle 112\rangle$. According to Inagaki ${ }^{16}$, the formation of the $\gamma$-fiber can occur by rotation along the following path: $\{110\}<001>$ $\{554\}<225>-\{111\}<112>-\{111\}<110>-\{223\}<110>$. Thus, the presence of the $\{110\}<001>$ and $\{554\}<225>$ components after the first annealing, as shown in Fig. 5, contributed to the increase in $\gamma$-fiber after the second cold rolling.

To evaluate the effect of cold rolling on the deformation texture, the results obtained for $80 \%$ and $60 \%$ were compared (Fig. 2 and Fig. 4), respectively. The texture developed for both reductions was very similar, with differences in intensity. From the deformation texture, it was observed that the increase in deformation from $60 \%$ to $80 \%$ intensified the $\alpha$-fiber and the $\gamma$-fiber, mainly the $\{001\}\langle 110\rangle$ and $\{111\}\langle 110\rangle$ components. For $60 \%$ of the deformation, the maximum intensity occurred at $\{335\}\langle 110\rangle, f(g)=9.13$, while for $80 \%$ the peak occurred at $\{001\}\langle 110\rangle, f(g)=13.8$. Thus, it was clear that a pronounced formation of the $\{001\}\langle 110\rangle$ component occurred with an increased reduction, given that the component showed a weak intensity in the annealed hot-rolled sample (Fig. 1). According to Ray et al. ${ }^{17}$, the increase of the $\{001\}\langle 110\rangle$ component with deformation occurs due to the stability of its orientation in extra-low carbon $\mathrm{Nb}$ and Ti stabilized steels. In case of the $\gamma$-fiber component, Hutchinson ${ }^{18}$ reported that the increase in strain during cold rolling continuously enhances the $\{111\}\langle 110\rangle$ component for a low carbon steel. These findings agree with the similar results observed by Huh and Engler ${ }^{7}$, who showed that after the increase in reduction from $60 \%$ to $80 \%$, the enhanced $\{001\}\langle 110\rangle$ and $\{111\}\langle 110\rangle$ components appeared in a $17 \% \mathrm{Cr}$ ferritic stainless steel.

The influence of cold rolling on the recrystalization texture can be observed in Fig. 3 and Fig. 5. The increase in $\gamma$-fiber intensity was observed, primarily in the $\{111\}\langle 112\rangle$ component, with strain enhancement $(60 \%$ to $80 \%)$. Prior literature reports that the $\{111\}\langle 112\rangle$ components nucleate within $\{111\}\langle 110\rangle$ and $\{112\}\langle 110\rangle$ deformed grains ${ }^{10}$. Therefore, the highest intensity after $80 \%$ of the cold-rolled sample (Fig. 2) favored the formation of the $\{111\}\langle 112\rangle$ components after annealing. According to Gao et al. ${ }^{19}$, the weak texture after cold rolling is unfavorable for the intensification of the recrystallization texture. Thus, it could be concluded that the stronger texture after $80 \%$ of reduction improved the $\gamma$-fiber intensity. In the case of $60 \%$ in cold rolling, the $\{110\}\langle 001\rangle$ Goss component was also developed, as shown in Fig. 5. Raabe and Lücke ${ }^{15}$ reported an increase in the $\{110\}\langle 001\rangle$ Goss fraction of up to $70 \%$ in cold rolling; above this reduction, the fraction drastically reduces. The $\{110\}\langle 001\rangle$ Goss grains nucleate in the early stage of recrystallization within the shear band in $\{111\}\langle 112\rangle$ deformed grains ${ }^{15,20}$. From the deformation texture (Fig. 2 and Fig. 4), it was observed that the $\{111\}$ $\langle 112\rangle$ components presented an intensity that was similar to the increase in deformation. This indicates that the increase in $\{110\}\langle 001\rangle$ Goss fraction is closely related to the nucleation rate during recrystallization. The nucleation rate increased when the percentage of cold-rolled was enhanced due to the amount of energy stored during deformation ${ }^{21,22}$. Thus, for the lower reduction and nucleation rate, the $\{110\}\langle 001\rangle$ Goss nuclei have a chance of growing at the expense of deformed grains.

The recrystallization texture development after the final annealing was remarkably affected (Fig. 3 and Fig. 7). The formation of the recrystallization texture depends on the 
initial deformation texture ${ }^{15}$. As mentioned above, $\{111\}$ $\langle 112\rangle$ recrystallized grains nucleate in $\{111\}\langle 110\rangle$ recovery grains or vice-versa ${ }^{10}$. In the present study, it was observed that the $\{111\}\langle 110\rangle$ component was more intense after direct rolling than with an intermediate annealing for $80 \%$ cold rolling (Fig. 2 and Fig.6), respectively. Thus, the $\{111\}\langle 110\rangle$ orientation present in the rolling texture favored a more pronounced development of the $\{111\}\langle 112\rangle$ component after final annealing, as shown in Fig. 3. On the other hand, the strong $\gamma$-fiber after cold rolling (Fig.6) led to the development of a more uniform $\gamma$-fiber after the sample's final annealing in an intermediate annealing route. Furthermore, the fine grains in the intermediate annealing sample (Fig. 5) favored the development of the $\gamma$-fiber. Prior literature reports that $\gamma$-fiber fraction tend to be enhanced with the reduction in grain size of hot rolled sample ${ }^{11}$. Yah et al. ${ }^{8}$ reported that intermediate annealing enhances the intensity and improves the uniformity of the $\gamma$-fiber in $\mathrm{Nb}$-Ti stabilized ferritic stainless steel containing $11 \% \mathrm{Cr}^{8}$. By contrast, in a study conducted by Huh and Angler ${ }^{7}$, the texture obtained by the route with intermediate annealing showed the $\gamma$-fiber and $\alpha$-fiber after final annealing. The $\gamma$-fiber was very non-uniform, and the maximum occurred close to $\{111\}\langle 011\rangle$.

Intermediate annealing reduced the banding factor and gradient texture, as demonstrated by the uniformity factor (Table 1). These results indicate that intermediate annealing affects both nucleation and spatial distribution in the matrix. During recrystallization, nucleation occurs in regions with high stored energy ${ }^{21-23}$. In addition, the driving force for recrystallization depends on the stored energy, which is related to the crystallographic texture. Some authors $17,24,25$ have reported that the $\gamma$-fiber grains are able to store more energy than $\alpha$-fiber grains. Considering the results shown in Table 1 and the cold rolling texture obtained after an $80 \%$ reduction for both routes (Fig. 2 and Fig. 6), respectively, the effect of the texture on recrystallization was noted. In the direct reduction, the $\alpha$-fiber and $\gamma$-fiber comprised the texture, thus the nucleation begins preferably in $\gamma$-fiber grains due to the high energy stored. At the same time, the $\alpha$-fiber grains are undergoing a recovery process. This condition ( $\alpha$-fiber and $\gamma$-fiber) produces a highly heterogeneous nucleation in the microstructure. On the other hand, for the intermediate annealing route, the $\gamma$-fiber was predominant, and thus the nucleation was more homogenous in the microstructure. According to Huh et al. ${ }^{26}$, the steel with a more banded microstructure, containing pronounced orientation colonies, tends to form surface defects, determined by ridging, while homogenous distribution is generally free from ridging.

The results showed that formability was improved when intermediate annealing was added. Yazawa et al. ${ }^{11}$ reported that the $\bar{r}$ value is related to the $\gamma$-fiber in the recrystallization texture. Furthermore, the enhancement and uniformity of the $\gamma$-fiber is essential in order to improve the $\bar{r}$ value ${ }^{10-12}$. From the results shown in Table 1, a remarkable difference in the $\gamma$-fiber fraction among the two routes was not obtained. The main differences occurred in the $\gamma$-fiber uniformity and the $\theta$-fiber fraction. Gao et al. ${ }^{27}$ demonstrated that the uniform $\gamma$-fiber recrystallization texture was beneficial in the enhancement of the $\bar{r}$ value. Moreover, some authors ${ }^{17,28}$ have reported that $\theta$-fiber is unfavorable when attempting to obtain a high $\bar{r}$ value. Hamada et al. ${ }^{12}$ demonstrated that the $\bar{r}$ value for the $\{100\}\langle 011\rangle$ and $\{100\}\langle 001\rangle$ orientations are notably low in almost all directions. The reduction of the $\theta$-fiber fraction, from the 0.11 to 0.08 , obtained with the addition of intermediate annealing improves the $\bar{r}$ value, and the $\gamma / \theta$ ratio reached approximately 5.25. It should be mentioned that the $\gamma / \theta$ ratio is an important parameter used to compare the capacity of deep drawability.

\section{Conclusions}

This study investigated the influence of intermediate annealing on the microstructure, texture, and formability of $\mathrm{Nb}$-stabilized ferritic stainless steel. The results led to the following conclusions:

I Cold rolling by direct reduction led to the development of the $\alpha$-fiber and the $\gamma$-fiber, with a gradient between the surface and the center region. The increase in deformation from $60 \%$ to $80 \%$ intensified the $\alpha$-fiber and the $\{111\}\langle 011\rangle$ component. The texture gradient was generated from the texture gradients already present in the annealed hot-rolled sample.

II The strong $\gamma$-fiber, with peak at $\{111\}\langle 112\rangle$, was developed after cold rolling for the intermediate annealing route. The surface and center showed a similar intensity along the fiber. The increase in the $\gamma$-fiber was attributed to the presence of $\{110\}\langle 001\rangle$ and $\{554\}\langle 225\rangle$ components before cold rolling.

III The addition of intermediate annealing resulted in a more uniform $\gamma$-fiber, and reduced the texture gradient, factor banding, and $\theta$-fiber fraction after the final annealing. These results were attributed to the strongest $\gamma$-fiber and weak texture gradient in a cold-rolled texture.

IV The increase in $\bar{r}$ value was obtained by inserting intermediate annealing between the cold rolling steps. This finding was related to the development of a uniform $\gamma$-fiber and a reduced $\theta$-fiber after the final annealing.

\section{Acknowledgments}

The authors wish to acknowledge Fundação de Amparo à Pesquisa de Minas Gerais (Fapemig), Conselho Nacional de Desenvolvimento Científico e Tecnológico (CNPq), Comissão de Aperfeiçoamento de Pessoal do Nível Superior (Capes-PROEX), and Aperam South America. 


\section{References}

1. Liu H, Liu Z, Wang G. Texture Development and Formability of Strip Cast $17 \%$ Cr Ferritic Stainless Steel. ISIJ International. 2009;49(6):890-896.

2. Yan $\mathrm{H}, \mathrm{Bi} \mathrm{H}, \mathrm{Li} X, \mathrm{Xu} \mathrm{Z}$. Microstructure and texture of $\mathrm{Nb}+$ Ti stabilized ferritic stainless steel. Materials Characterization. 2008;59(12):1741-1746.

3. Patra S, Ghosh A, Sood J, Singhal LK, Podder AS, Chakrabarti D. Effect of coarse grain band on the ridging severity of 409L ferritic stainless steel. Materials \& Design. 2016;106:336-348.

4. Braga FV, Escobar DP, Reis TJA, de Oliveira NJL, Andrade MS. Recrystallization of niobium stabilized ferritic stainless steel during hot rolling simulation by torsion tests. Journal of Materials Research and Technology. 2016;5(1):92-99.

5. Siqueira RP, Sandim HRZ, Oliveira TR. Texture evolution in $\mathrm{Nb}$-containing ferritic stainless steels during secondary recrystallization. Materials Science and Engineering: A. 2008;497(1-2):216-223.

6. Lee KM, Huh MY, Park S, Engler O. Effect of Texture Components on the Lankford Parameters in Ferritic Stainless Steel Sheets. ISIJ International. 2012;52(3):522-529.

7. Huh MY, Engler O. Effect of intermediate annealing on texture, formability and ridging of $17 \% \mathrm{Cr}$ ferritic stainless steel sheet. Materials Science and Engineering: A. 2001;308(1-2):74-87.

8. Yan H, Bi H, Li X, Xu Z. Effect of two-step cold rolling and annealing on texture, grain boundary character distribution and r-value of $\mathrm{Nb}+\mathrm{Ti}$ stabilized ferritic stainless steel. Materials Characterization. 2009;60(1):65-68.

9. Jung I, Mola J, Chae D, De Cooman BC. Influence of the Cold Rolling and Annealing Sequence on the Ridging Behaviour of Ti-Stabilized 18\% Cr Ferritic Stainless Steel. Steel Research International. 2010;81(12):1089-1096.

10. Gao F, Liu ZY, Liu HT, Zhang SM, Dong AM, Hao YS, et al. Development of y-fibre recrystallisation texture in mediumchromium ferritic stainless steels. Materials Science and Technology. 2014;30(14):1735-1741.

11. Yazawa Y, Ozaki Y, Kato Y, Furukimi O. Development of ferritic stainless steel sheets with excellent deep drawability by $\left\{\begin{array}{lll}1 & 1 & 1\end{array}\right\}$ recrystallization texture control. JSAE Review. 2003;24(4):483-488.

12. Hamada J, Ono N, Inoue H. Effect of Texture on r-value of Ferritic Stainless Steel Sheets. ISIJ International. 2011;51(10):17401748 .

13. Bunge HJ. Texture Analysis in Materials Science. London: Butterworth-Heinemann; 1982. 614 p.
14. Raabe D. Rolling and anealling textures of a ferritic stainless steel with 11 mass \%Cr content. In: Proceedings of the Eleventh International Conference on Textures of Maerials (ICOTOM 11); 1996 Sep 16-20; Xi'an, China. p. 330-335.

15. Raabe D, Lüucke K. Textures of ferritic stainless steels. Materials Science and Technology. 1993;9(4):302-312.

16. Inagaki H. Fundamental Aspect of Texture Formation in Low Carbon Steel. ISIJ International. 1994;34(4):313-321.

17. Ray RK, Jonas JJ, Hook RE. Cold rolling and annealing textures in low carbon and extra low carbon steels. International Materials Reviews. 1994;39(4):129-172.

18. Hutchinson B. Deformation microstructures and textures in steels. Philosophical Transactions of Royal Society A. Mathematical, Physical and Engineering Sciences. 1999;357(1756):1471-1485.

19. Gao F, Yu F, Misra RDK, Zhang XJ, Zhang SM, Liu ZY. Microstructure, Texture, and Deep Drawability Under Two Different Cold-Rolling Processes in Ferritic Stainless Steel. Journal of Materials Engineering and Performance. 2015;24(10):3862-3880.

20. Park JT, Szpunar JA, Cha SY. Effect of Heating Rate on the Development of Annealing Texture in Nonoriented Electrical Steels. ISIJ International. 2003;43(10):1611-1614.

21. Abbaschian R, Abbaschian L, Reed-Hill RE. Physical Metallurgy Principles. $4^{\text {th }}$ ed. Boston: Cengage; 2009. 750 p.

22. Humphreys FJ, Hatherly M. Recrystallization and related Annealing Phenomena. Oxford: Elsevier; 2004. 574 p.

23. Doherty RD, Hughes DA, Humphreys FJ, Jonas JJ, Jensen DJ, Kassner ME, et al. Current issues in recrystallization: A review. Materials Science and Engineering: A. 1997;238(2):219-274.

24. Du W, Jiang LZ, Sun QS, Liu ZY, Zhang X. Microstructure, Texture, and Formability of Nb+Ti Stabilized High Purity Ferritic Stainless Steel. Journal of Iron and Steel Research, International. 2010;17(6):47-52.

25. Gao F, Liu ZY, Liu HT, Wang GD. Evolution of ThroughThickness Texture in Ultra Purified 17\% Cr Ferritic Stainless Steels. Journal of Iron and Steel Research, International. 2013;20(4):31-38.

26. Huh MY, Lee JH, Park SH, Engler O, Raabe D. Effect of Through-Thickness Macro and Micro-Texture Gradients on Ridging Of 17\%Cr Ferritic Stainless Steel Sheet. Steel Research International. 2005;76(11):797-806.

27. Gao F, Liu Z, Liu H, Wang G. Texture evolution and formability under different hot rolling conditions in ultra purified $17 \% \mathrm{Cr}$ ferritic stainless steels. Materials Characterization. 2013;75:93-100.

28. Hutchinson WB. Development and control of annealing textures in low-carbon steels. International Materials Reviews. 1984;29(1):25-42. 